\title{
Inflation Forecasts: Are Market-Based and Survey-Based Measures Informative?
}

\author{
Magdalena Grothe $^{1}$ \& Aidan Meyler ${ }^{1}$ \\ ${ }^{1}$ European Central Bank, Frankfurt, Germany \\ Correspondence: Aidan Meyler, European Central Bank, 60640 Frankfurt, Germany.
}

Received: November 1, 2017

Accepted: January 8, 2018

Online Published: January 17, 2018

doi:10.5430/ijfr.v9n1p171

URL: https://doi.org/10.5430/ijfr.v9n1p171

\begin{abstract}
This paper analyses the predictive power of market-based and survey-based inflation expectations for actual inflation. We use the data on inflation swaps and the forecasts from the Survey of Professional Forecasters for the euro area and the United States. The results show that both market-based and survey-based measures have a non-negligible predictive power for inflation developments, as compared to statistical benchmark models. Therefore, for horizons of one and two years ahead, market-based and survey-based inflation expectations actually convey information on future inflation developments.
\end{abstract}

Keywords: inflation, expectations, forecasting, swaps, surveys, market, professional forecasters

\section{Introduction}

Models used for inflation forecasting are usually based on statistical time series properties of inflation and on information regarding economic variables. This paper analyses whether the information on inflation expectations has predictive power for actual inflation. We show that short-term inflation expectations derived from survey and market data for the euro area and United States are informative predictors of future inflation developments.

For market-based measures of inflation expectations, the paper focuses on inflation-linked swaps. In these contracts, a fixed inflation swap rate is exchanged against the realised inflation rate over an agreed period of time. The fixed leg of the swap can be thus interpreted as a measure of investors' inflation expectations over a certain contract duration. For survey-based measures of inflation expectations, the paper focuses on the results from the Survey of Professional Forecasters conducted by the European Central Bank for the euro area and the Federal Reserve Bank of Philadelphia for the United States. A relatively large panel of respondents in this survey assures a good data quality, as compared to other surveys available on inflation. With respect to the forecast horizon, we focus on the shorter-term measures, to ensure that the analysis of the forecasting performance is statistically feasible, given the size of the samples.

This paper contributes to the literature by providing evidence that market-based and survey-based measures of inflation expectations are informative sources of information on future inflation. Assessing the actual performance of various measures of inflation expectations is important given the key role ascribed to inflation expectations in the inflation generating process. The usefulness of survey-based measures of inflation expectations in forecasting inflation has been documented in Ang, Bekaert, and Wei (2007). In a similar vein, Gil-Alana, Moreno, and Perez de Gracia (2012) report that, for the United States, survey-based expectations outperform standard time series models. However, in a more recent study, Trehan (2015) shows that the forecast accuracy of household and professional inflation surveys has deteriorated. With respect to the role of financial indicators for forecasting inflation and output, Stock and Watson (2003) find that some asset prices predict inflation in some countries in some periods, but without any stable patterns. Assessing the forecast performance of market-based measures of inflation expectations has not been possible until most recently due to relatively short time series.

In a comprehensive overview of available forecasting models, Faust and Wright (2013) compare the forecasting performance of various approaches and show that simple statistical benchmarks like an autoregressive process are very difficult to outperform. They also indicate that information from the prices of inflation-linked assets could be indicative for inflation. In contrast, Bauer and McCarthy (2015) argue that market-based and survey-based measures contain little forward-looking information about future inflation. Still, evidence on the forecasting performance of market-based measures of inflation expectations for inflation, also in comparison to survey-based measures, is not yet established in the literature. This paper fills this gap by analysing the forecasting performance of market-based and survey-based inflation expectations for the two largest currency areas.

Market-based and survey-based measures of inflation expectations have both their advantages and drawbacks. 
Market-based inflation expectations are very timely, available at high frequency, and based on the financial transactions among numerous market participants. However, market prices include also compensation for risk and liquidity premia, which may at times distort the signals about inflation expectations, especially at longer horizons. Survey information delivers a direct estimate of the probability distribution of certain inflation outcomes at certain horizons. The drawback here is that the frequency of surveys is rather low, and the panel of respondents is in some cases limited. Taking these features into account, as well as in view of relatively short time series, there is still scarce evidence in the existing literature related to the information content of market-based and survey-based measures of inflation expectations.

The results of this paper show that both types of signals have a non-negligible predictive power for inflation developments, as compared to statistical benchmark models.

For horizons of one and two years ahead, market-based and survey-based inflation expectations actually convey information on future inflation developments. This finding is in line with the practice employed in central banks, where both, market-based and survey-based measures of inflation expectations are monitored closely and cross-checked against each other (see, e.g., European Central Bank (2014b and 2012)).

The remainder of the paper is organised as follows: Section 2 discusses market and survey data on inflation expectations for the euro area and the United States, reporting also their descriptive statistics along with the data on HICP/CPI inflation. Section 3 compares the forecasting performance of measures of inflation expectations with benchmark time series models for inflation. Section 4 concludes.

\section{Data}

This section discusses the data on inflation markets and inflation surveys for the euro area and United States. More detailed methodological aspects are discussed on the example of the euro area data. The final part of this section presents descriptive statistics of the market and survey data, along with the summary of the corresponding HICP/CPI inflation developments.

\subsection{Market Data}

Market-based measures of inflation expectations can be derived from inflation bond and swap markets for horizons of up to ca. 10 years ahead. In the following analysis, the focus is set on the swap market measures. (Note 1) An inflation swap is a derivative contract, by which one counterparty is entitled to receive a payment equal to the nominal value times the realised inflation rate over an agreed period of contract duration (e.g. one year) in exchange for the nominal value times a given fixed rate of inflation (see Figure 1). This fixed rate, the fixed leg of the inflation swap, reflects the expected rate of inflation over the contract horizon, as priced by investors. As a result of the contract, only flows related to the difference between expected and realised inflation are exchanged at the agreed horizon.

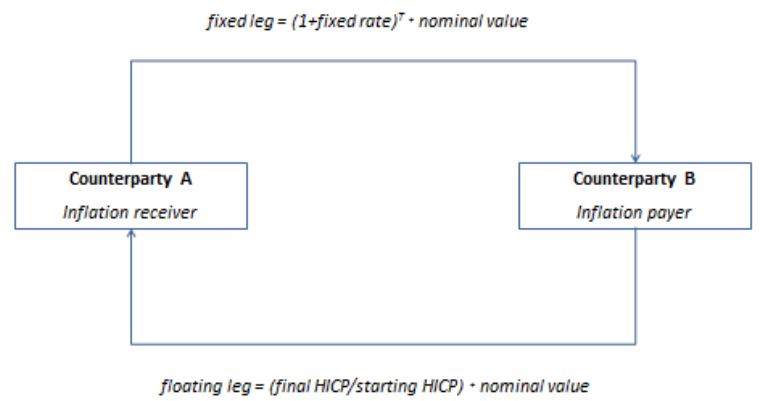

Figure 1. Payment structure of the inflation swap

Note: The figure presents the payment structure of a zero-coupon inflation swap. Two involved counterparties, inflation receiver (counterparty A) and inflation payer (counterparty B) exchange payments at the maturity time $T$, based on a nominal value of the notional. Inflation payer pays a realised rate of inflation, with respect to the starting value of the price index. The starting value of the index is HICP excluding tobacco (euro area) and CPI (United States) at time $t-3$ months (with a switch in the index at the end of the month). Inflation receiver pays a fixed rate on the nominal value, called inflation swap rate. Such a set-up of the contract means that at the time of swap transaction, already two to three months of the realised inflation are known. 
We use daily data on inflation swap rates provided by Reuters. In order to match the frequency of the HICP and CPI inflation, the data on inflation swap rates is aggregated from the daily to monthly frequency by taking end-of month observations. This ensures that all information available until the last day of the month is incorporated in the inflation swap price. For the forecasting horizon of one year, we use 1-year spot rates; while for the forecasting horizon of two years, we compute 1-year forward rates one year ahead. The data covers the period from March 2005 to April 2015. Analysing inflation swap rates as indicators of HICP/CPI inflation expectations, several aspects need to be taken into account. This holds in particular when comparing these measures with information based on other sources, e.g., surveys or economic forecasts:

(i) For the euro area, the inflation underlying an inflation swap contract is calculated with respect to the index of euro area HICP excluding tobacco (HICPxT) three months before the current date of the contract (indexation lag). This means, for example, that a 1-year swap rate at time $t$ would measure a market-based expectation of HICPxT inflation over one year from $\mathrm{t}-3$ months to $\mathrm{t}+9$ months. This implies that information included in a 1-year inflation swap reflects 3 months of actual inflation data and expectations over a 9-month horizon. Therefore, mechanically, it reacts to current HICP realisations, and has a shorter forecast horizon than surveys, which ask at time $t$ for expectations one year ahead. For longer horizons, forward inflation swap rates can be used, which mitigates the mechanical relation with the realised HICP.

(ii) Indexing to HICPxT should not imply a large systematic discrepancy, when regarding inflation swap rates as a measure of market-based expectations of HICP, since the discrepancy between both inflation rates tends to fluctuate within a small range of up to10 basis points (see Figure 2), mostly under the influence of specific taxes on tobacco. (Note 2) On average, the annual rate of change in the HICPxT has tended to be marginally (around 6 basis points) lower than HICP inflation, which should not cause large discrepancies in terms of comparing inflation swap rates with realised HICP inflation rates.

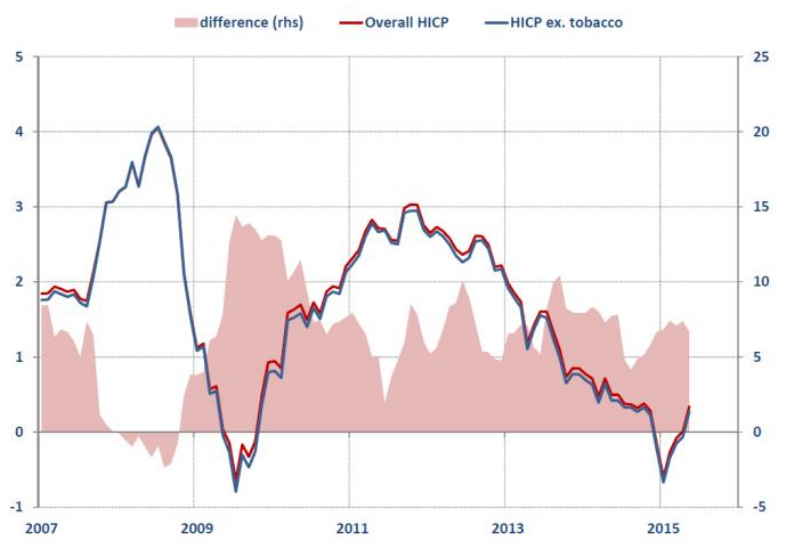

Figure 2. Comparison of euro area HICP and HICPxT inflation

Note: The figure presents HICP and HICP excluding tobacco (left-hand scale, in percentage points) and the difference between them (right-hand scale, in basis points).

(iii) Inflation swap contracts are traded instruments, which implies that the information embedded in the prices reflects an aggregation of views of numerous market participants, as based on their actual investment decisions. In periods of market tensions, liquidity in these markets may fluctuate, but in general, observed pricing reflects actually binding quotes and actively traded contracts (see. e.g. Fleming and Sporn (2013)).

(iv) Inflation swap rates include not only information about market participants' inflation expectations, but also the respective risk premium. It is related to inflation risk, i.e. the unexpected changes in inflation over the period of the swap contract (see, e.g. European Central Bank (2014a) and Pflueger and Viceira (2011)). One of the key advantages of swaps, however, is that, unlike for bond-based break-even inflation rates, liquidity effects are limited as only residual cash flows are exchanged at maturity (and not the whole notional value of the contract). (Note 3) Still, inflation swaps can be additionally affected by the counterparty credit risk. 


\subsection{Survey Data}

Survey-based measures of inflation expectations for the euro area are available from the Survey of Professional Forecasters conducted by the European Central Bank (ECB). For the United States, the Survey of Professional Forecasters is conducted by the Federal Reserve Bank of Philadelphia. Since 1999 the ECB SPF for the euro area has been conducted quarterly. (Note 4) On average, the survey has had an active panel of approximately 75 professional forecasters with an actual participation in each round of about 60 respondents on average (see Figure 3). (Note 5) This survey is based on responses from financial and other (mainly research) institutions from around the European Union. Approximately $60 \%$ of the panel are financial institutions and around $80 \%$ of the panel are located in the euro area. In this respect, covering a broader set of respondents than only financial market participants, SPF may be argued to sample a broader array of expectations than those reflected in the market-based measures. (Note 6) Surveys also have the advantage that they provide an integrated macroeconomic perspective (i.e. on prices, output and unemployment), at the individual level of particular respondents.

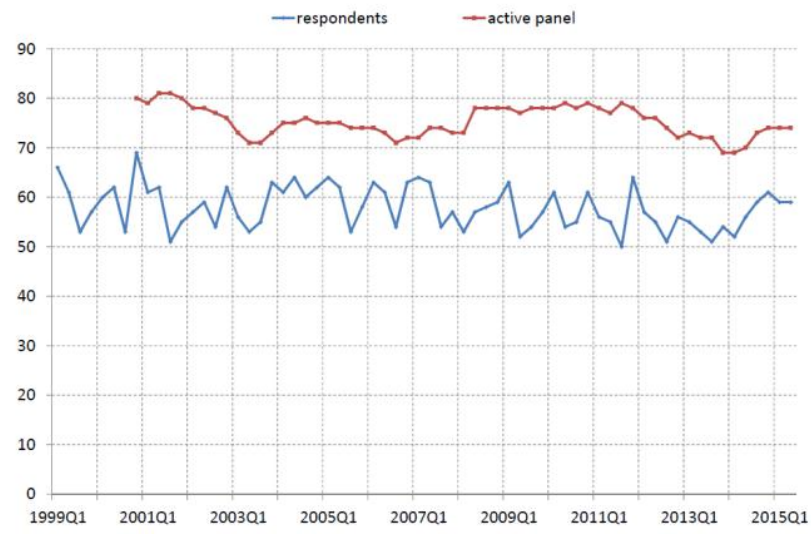

Figure 3. Active panel and participation rate in the ECB's SPF

Note: Active panel defined as participants who have participated in one of the previous eight quarters.

Sources: ECB and authors' calculations.

The horizon of the SPF surveys covers the period of up to 5 years ahead for the euro area, with questions related to 1-year and 2-years ahead, as well as to particular calendar years (the current and two following years). For the United States, the period covered by the survey extends only to around 1.5 years. In the following analysis, we focus on 1-year and 2-year horizons, in order to match with the results for market-based data.

Analysing survey measures as indicators of HICP/CPI inflation expectations, several aspects need to be taken into account, in particular when comparing them to the market-based measures:

(i) Frequency and timing of the survey: As indicated above, both the ECB and US SPFs are conducted four times a year but are scheduled differently. The ECB SPF is conducted mid-January, mid-April, mid-July and mid-October, whereas the US SPF is carried out in mid-February, mid-May, mid-August and mid-November. The timing of the ECB SPF has been chosen to coincide with the release of euro area HICP (Harmonised Index of Consumer Prices) data for the previous month (i.e. December, March, June and September respectively). (Note 7) The implications arising from the design of the survey schedule for the forecast evaluation exercise are discussed in more detail below.

(ii) Inertia: One potential disadvantage of survey-based forecasts is that not only are they relatively infrequent but also their timing may not coincide with the forecast schedule of the panel members. Therefore, their reported forecast may not be revised and not reflect the latest available macroeconomic data. Meyler and Rubene (2009) surveyed respondents to the ECB SPF and found that a majority of respondents (84\%) reported that their forecasts are updated on a regular calendar basis and that around one-third indicated that they update their forecasts following data releases or other events relevant to their forecasts. (Note 8) Overall, given the high frequency of regular updates and the fact that respondents additionally adjust their forecasts in exceptional circumstances, the replies suggest that the SPF responses are indeed quite timely. In this context, there appears to be some correlation between the length of the 
forecast horizon and the frequency with which forecasts are revised. On average since 1999, from one round to the next approximately $80 \%$ of ECB SPF respondents revise their forecasts for one-year ahead inflation; $70 \%$ for inflation two-years ahead, and 30\% for inflation five years ahead.

(iii) Unbalanced panels: The composition of the active SPF panel changes from one round to the next, reflecting the voluntary nature of the survey and other idiosyncratic effects. However, given the relatively large number of participants on average (around 60 out of ca. 75), changes in composition are unlikely to have a material effect on the average forecast. Indeed, the correlation between changes in the one-year ahead inflation forecast from the unbalanced and balanced (i.e. only those participating in two consecutive rounds) is 0.97 (and 0.90 for the two-year ahead forecasts). Furthermore, survey-based forecasts based on the average consensus may be useful benchmarks as the forecasting literature has shown that it is generally difficult to identify in real-time an individual forecaster or forecast technique that robustly outperforms the consensus forecast (see, e.g. Genre et al. (2013) for the euro area and D'Agostino et al. (2012) for the US). (Note 9)

Given the relatively strong $(60 \%)$ participation of financial institutions in the panel of the SPF, there may be some relationships between survey-based inflation expectations and market-based measures. However, the information content of survey and market indicators is still different to some extent, for example due to the fact that market-based measures incorporate also inflation risk pricing. Moreover, anecdotal information received from some SPF participants within financial institutions (these are usually based in the Economic Research Department), suggests that whilst traders in each institution are informed about the forecasts of the SPF panellists, they could still take positions based on their own trading views and perceptions of market conditions. In this context, the comparison of the forecasting performance for survey- and market-based inflation forecasts helps understanding potential differences in information content of these measures.

\subsection{Relation between Market-Based and Survey-Based Expectations}

As discussed above, measures of inflation forecasts for one- and two-years ahead from market- and survey-based data include different information sets, which must be taken into account when comparing forecast performance. In the case of the ECB SPF, the schedule of the survey is constructed in a way which ensures that the panellists have the most recent inflation data, which refers to twelve months before the forecast horizon, when they receive the questionnaire. (Note 10) In this way, the one-year ahead horizon is exactly twelve months ahead of the latest available inflation data. For swaps, the contract is constructed in a way, in which the settlement on a given day is based on the value of the reference price index three months before. This implies that the "one-year" ahead swap forecast is in fact a nine-month ahead forecast. (Note 11)

The impact of these differences in information sets may be seen in Figures 4 and A-1, which visually compare the one-year ahead inflation forecasts from the ECB SPF and euro area swaps (for the two-year horizon, see Figure A-2 in the Appendix). Panel (a) of Figure 4 shows the one-year ahead inflation forecast from the SPF since 1999. Among important features, first, a majority of errors are positive (76\% of outcomes) and quite persistent, with an AR(1) coefficient of 0.79. (Note 12) Second, the SPF forecasts do not appear to anticipate the large swings in inflation observed between 2008 and 2014. They did move down in 2009 Q3 (but this lagged the decline in actual inflation by one year). Panel (b) shows the one-year ahead inflation forecast from the swaps. At first glance these appear to capture better the swings in actual inflation. However, a visual comparison of errors shows broadly similar patterns among both measures. Further figures of forecast errors are presented in the Appendix, accounting for the indexation lag of the swap contract (Figure A-1, Panel a), seasonal patterns of inflation (Figure A-1, Panel b), and a longer forecast horizon of 2 years (Figure A-2). 


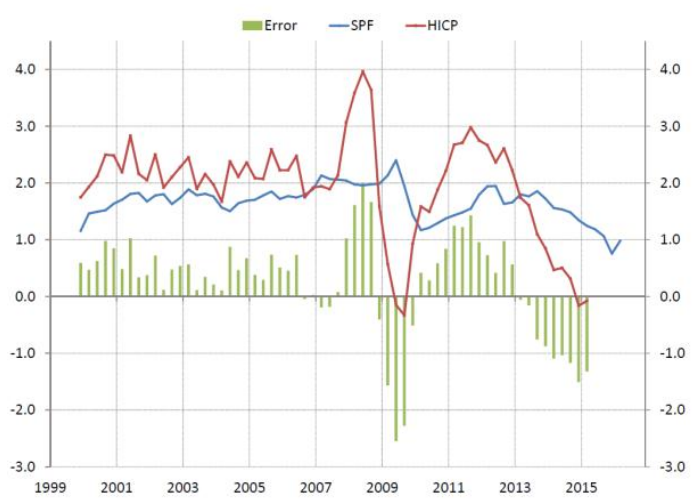

(a) SPF and HICP

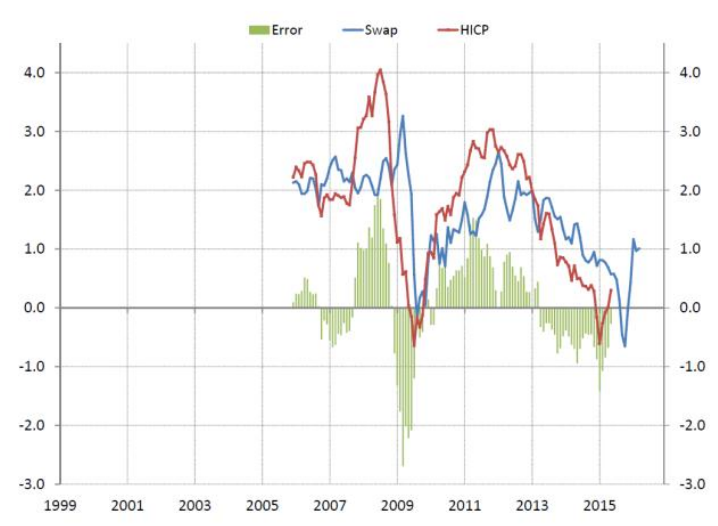

(b) Swap and HICP

Figure 4. One-year ahead inflation forecasts from surveys and swaps

Note: The figure presents a comparison of forecasts, as based on SPF and swaps with the realised HICP for the euro area. Panel (a) shows the one-year ahead inflation forecast from the SPF. Panel (b) shows the same for the 1-year swap.

Overall, market-based and survey-based measures of inflation expectations are not directly comparable, owing to the described differences in construction and features. Therefore, to investigate the forecast performance, we use a set of benchmarks, including an autoregressive (AR) process, a random walk and a constant $2 \%$ inflation. In this way, we compare the forecasting performance of market-based and survey-based measures indirectly. Still, the results need to be interpreted with caution, as these measures are of different frequency and based on different information sets.

\subsection{Descriptive Statistics}

To summarise the underlying relationships between inflation expectations, as derived from market and survey data, and realised HICP inflation, the following part discusses the descriptive statistics, as well as the correlation and causality structure among the analysed variables.

Table 1 presents the descriptive statistics of HICP, as well as expectations for 1-year and 2-year ahead horizons, as based on inflation swaps and SPF. We consider three samples: the whole period since 1999, where only SPF measures and HICP inflation are available, the period since the information on inflation swaps begins to be available, i.e. starting 2005, and the most recent period of the crisis, starting in 2009. The table shows that, generally, the mean of inflation expectations from market-based and survey-based measures is relatively close to the mean of the realised HICP inflation, in particular for the longer forecast horizon. Regarding the horizon of 1 year ahead, the surveys and the markets tend to be somewhat below the average realised inflation. In terms of the variability of these measures, the comparison of the standard deviations shows that HICP/CPI inflation tends to fluctuate around twice as much as swap-based inflation expectations 1 year ahead, and around 3-4 times as much as survey-based expectations and swap-based inflation expectations 2 years ahead.

In terms of the links among the analysed variables, Table 2 presents the correlation structure and the results of 
Granger causality tests between the swap-based/survey-based inflation expectations and inflation. The sample reported in the table starts in 2005. The results dating back to 1999 for the SPF are presented in Table A-1 in the Appendix. The correlation coefficients between inflation expectations and inflation are positive, but not very high. They also tend to decrease with the longer horizon of expectations and with the lag of inflation. Also, market-based expectations seem to be less correlated with inflation than survey-based measures. Regarding Granger causality, only few relations are statistically significant. In particular, inflation is found to Ganger-cause movements in swaps at 1-year horizon of inflation expectations, which is in line with the fact that 1-year swaps include already information on 3 months of realised inflation due to the indexation lag. Moreover, SPF-based expectations are found to Granger-cause inflation, which is in line with some commonly used economic models (e.g. Smets and Wouters (2003, 2007) or Stock and Watson (2010)), but might not necessary hold for particular sub-periods in the sample, e.g. the crisis period. No consistent indications of Granger causality can be found at the longer horizon of inflation expectations.

Table 1. Descriptive statistics of inflation, inflation swap rates and SPF

\begin{tabular}{|c|c|c|c|c|c|}
\hline \multicolumn{6}{|c|}{ EURO AREA } \\
\hline & HICP & Swap (1yr) & Swap (2yr) & SPF (1yr) & SPF (2yr) \\
\hline \multicolumn{6}{|c|}{ since 2009} \\
\hline Mean & 1.39 & 1.28 & 1.48 & 1.49 & 1.68 \\
\hline Std. Dev. & 1.04 & 0.61 & 0.42 & 0.29 & 0.17 \\
\hline Min. & -0.65 & -0.57 & 0.46 & 0.76 & 1.22 \\
\hline Max. & 3.03 & 2.56 & 2.13 & 1.95 & 1.93 \\
\hline Max.-Min. & 3.68 & 3.12 & 1.67 & 1.19 & 0.70 \\
\hline \multicolumn{6}{|c|}{ since 2005} \\
\hline Mean & 1.80 & 1.58 & 1.73 & 1.68 & 1.77 \\
\hline Std. Dev. & 1.06 & 0.69 & 0.51 & 0.35 & 0.19 \\
\hline Min. & -0.65 & -0.57 & 0.46 & 0.76 & 1.22 \\
\hline Max. & 4.06 & 3.12 & 2.79 & 2.40 & 2.11 \\
\hline Max.-Min. & 4.71 & 3.69 & 2.33 & 1.64 & 0.89 \\
\hline \multicolumn{6}{|c|}{ since 1999} \\
\hline Mean & 1.88 & - & - & 1.68 & 1.77 \\
\hline Std. Dev. & 0.89 & - & - & 0.29 & 0.16 \\
\hline Min. & -0.65 & - & - & 0.76 & 1.22 \\
\hline Max. & 4.05 & - & - & 2.40 & 2.11 \\
\hline Max.-Min. & 4.69 & - & - & 1.64 & 0.89 \\
\hline \multicolumn{6}{|c|}{ UNITED STATES } \\
\hline & CPI & Swap (1yr) & Swap (2yr) & SPF (1yr) & SPF (2yr) \\
\hline \multicolumn{6}{|c|}{ since 2009} \\
\hline Mean & 1.55 & 1.23 & 1.81 & 2.05 & - \\
\hline Std. Dev. & 1.77 & 0.90 & 0.42 & 0.11 & - \\
\hline Min. & -3.09 & -2.78 & -0.29 & 1.85 & - \\
\hline Max. & 4.65 & 2.80 & 2.54 & 2.34 & - \\
\hline \multirow{2}{*}{\multicolumn{6}{|c|}{ since 2005}} \\
\hline & & & & & \\
\hline Mean & 2.28 & 1.63 & 2.02 & 2.17 & - \\
\hline Std. Dev. & 1.96 & 1.22 & 0.69 & 0.20 & - \\
\hline Min. & -3.09 & -3.68 & -1.45 & 1.85 & - \\
\hline Max. & 6.77 & 3.42 & 3.12 & 2.61 & - \\
\hline Max.-Min. & 9.85 & 7.10 & 4.57 & 0.76 & - \\
\hline \multicolumn{6}{|c|}{ since 1999} \\
\hline Mean & 2.30 & - & - & 2.25 & - \\
\hline Std. Dev. & 1.60 & - & - & 0.22 & - \\
\hline Min. & -2.28 & - & - & 1.85 & - \\
\hline Max. & 6.51 & - & - & 2.85 & - \\
\hline Max.-Min. & 8.79 & - & - & 1.01 & - \\
\hline
\end{tabular}

Note: The table reports descriptive statistics of HICP/CPI inflation, inflation swaps and SPF in the periods since 2009, since 2005 and since 1999 for the euro area and the United States. Data on inflation swaps are not available for the period before 2005; data on US SPF are not available for the horizons higher than 1 year ahead. The data cover the period from March 2005 to April 2015, which implies 122 monthly observations since 2005 (76 since 2009) and 40 quarterly observations since 2005 (relevant for SPF, 65/25 since 1999/2009, respectively). 
Table 2. Correlation structure and Granger causality tests between inflation swap rates/SPF and inflation

\begin{tabular}{|c|c|c|c|c|}
\hline & EURO AREA & \multirow[b]{2}{*}{2 year } & \multicolumn{2}{|c|}{ UNITED STATES } \\
\hline & 1 year & & 1 year & 2 year \\
\hline \multicolumn{5}{|c|}{ Correlation } \\
\hline swap-inflation & 0.41 & 0.30 & 0.51 & 0.41 \\
\hline swap-inflation(-1) & 0.33 & 0.15 & 0.24 & 0.28 \\
\hline SPF-inflation & 0.61 & 0.54 & 0.01 & - \\
\hline SPF-inflation(-1) & 0.28 & 0.28 & 0.44 & - \\
\hline \multicolumn{5}{|c|}{ Granger Causality } \\
\hline swap-inflation & & . & * & * \\
\hline inflation-swap & * & . & & * \\
\hline SPF-inflation & * & . & * & N/A \\
\hline inflation-SPF & & & * & N/A \\
\hline
\end{tabular}

Note: The table reports correlation coefficients between the first differences of swaps/SPF and inflation (in t and in t-1). F-statistics for the Granger causality test denotes the test for causality from, e.g., swap to inflation, when the row is labelled "swap-inflation". Tests are run on quarterly data for SPF and monthly for inflation swaps. Star reports a statistically significant result at the 99\% confidence level. The analysed samples cover the period: March 2005 - April 2015 for swaps (122 monthly observations), and March 2005 - April 2015 for SPF (40 quarterly observations).

\section{Methodology and Results}

This section presents a test of forecasting performance of market-based and survey-based inflation expectations at the horizons of one and two years ahead.

Starting with an example for the euro area, the paths of one-year inflation expectations derived from inflation swaps seem to contain information about the future developments in inflation. Figure 5 shows market-implied paths of future inflation, as priced during turning points of HICP. These selected examples show that such paths seem to be quite indicative, not least as they incorporate timely information about some components of HICP, for example commodity prices. For example, in July 2009, when HICP inflation was below $0 \%$, inflation swaps implied an increase in inflation, partly due to the realised three months of HICP and due to observed commodity market developments. This path indeed corresponded to the following HICP developments. Also paths pricing inflation declines, for example in times of high oil price inflation like in November 2011, were quite indicative of the direction and speed of the HICP adjustment. Similar signals can be obtained when looking at the paths implied by the surveys, and by comparing both information sources (see, e.g., European Central Bank (2014b, 2012, or 2011b)).

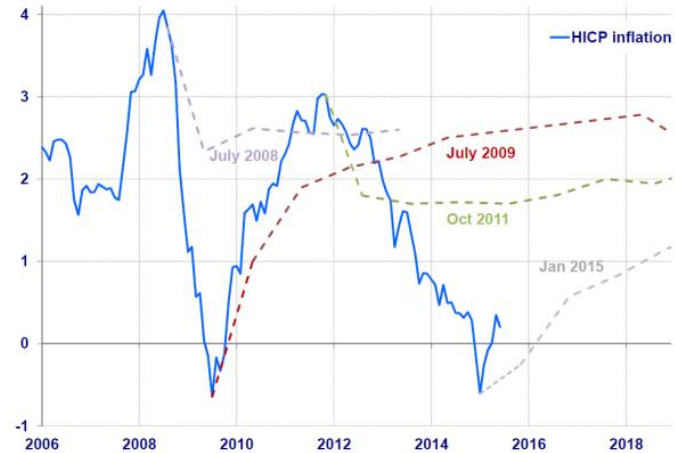

Figure 5. Paths of one-year forward swap rates at the turning points of HICP inflation

Note: The figure presents the one-year forward paths, based on the term structure of inflation swap rates, as observed during the months when HICP inflation was just before its turning point. Labels correspond to the month of peak/trough in inflation; the forward curve is computed in the middle of the following month, before any data on the next inflation outcome is available.

The analysis of the performance of inflation swaps in forecasting inflation needs to take into account the 3-month indexation lag of inflation swaps. It means that 1-year inflation swap rates need to be (i) adjusted for three initial months of HICP inflation, already released at the time when the swap is quoted, and (ii) compared with year-on-year HICP developments 9 months later, also adjusted for three initial months. (Note 13) For the horizon of two years ahead, 1-year forward inflation swap rate one year ahead (without any adjustment) needs to be compared to 
year-on-year HICP developments 21 months later. Regarding the performance of SPF expectations, no base effect-related adjustments are necessary, as the panel members are asked to forecast year-on-year HICP inflation in one year's time.

A more formal forecast performance compares short-term inflation swaps and SPF with forecasts based on standard time series processes for the HICP (random walk and auto-regression) as well as with constant expectations assumed at $2 \%$. We estimate the benchmark AR(1) model for the full sample, which allows us to avoid the issues of changing parameters and short estimation sample. This approach, using the information set available only at the end of the sample and making the parameter constant over time, gives a clear advantage to the benchmark model in the further comparison to inflation expectations measures. (Note 14 ) The estimates of AR(1) process are approximately $\mu \approx 0.06$ and $\varphi \approx 0.97$, which results in a long-term HICP mean of somewhat below $2 \%$ (over the sample since 2006), which is broadly in line with the observed average.

Tables 3 and 4 present the forecast performance of the swap-based and survey-based measures, as well as benchmark models, in terms of mean errors and RMSE. Moreover, the tables compare the performance of inflation expectations measures and benchmark models, based on Theil's U and the Diebold and Mariano (1995) test statistics, adjusted to accommodate the feature of a small sample size (see Harvey, Leybourne, and Newbold (1997)). This approach broadly follows the methodology as implemented in Faust and Wright (2013), who choose to assess the forecasting performance of various models for inflation, by forecasting the US inflation gap, i.e. realised inflation minus trend level (as measured by long-term forecast from Blue Chip). For the euro area, the trend level is most likely close to constant, given the shorter sample and lower inflation variability. Therefore, in the euro area case, the forecast performance is measured directly with respect to HICP inflation. For the sake of comparability, we also take the same approach for the US. (Note 15) The sample reported in the tables starts in 2005. The results dating back to 1999 for the SPF are presented in Tables A-2 and A-3 in the Appendix. Robustness checks, which involve accounting for a moving-average structure in the forecast errors using Hansen (2010) method for estimating MSFE are reported in Tables A-4 and A-5.

Table 3. Comparison of forecast performance of inflation swap rates and SPF with benchmarks - Euro area

\begin{tabular}{|c|c|c|c|c|}
\hline & 9 months ahead & 4 quarters ahead & 21 months ahead & 8 quarters ahead \\
\hline \multicolumn{5}{|c|}{ Mean Error } \\
\hline swap & 0.07 & - & -0.19 & - \\
\hline SPF & - & 0.02 & - & -0.11 \\
\hline RW & -0.17 & -0.23 & -0.37 & -0.38 \\
\hline AR & -0.01 & 0.05 & 0.02 & 0.13 \\
\hline $2 \%$ & -0.24 & -0.24 & -0.29 & -0.28 \\
\hline \multicolumn{5}{|c|}{ Root Mean Squared Error } \\
\hline swap & 0.87 & - & 1.16 & - \\
\hline SPF & - & 1.13 & - & 1.22 \\
\hline RW & 1.23 & 1.53 & 1.71 & 1.76 \\
\hline AR & 1.14 & 1.29 & 1.44 & 1.32 \\
\hline $2 \%$ & 1.11 & 1.13 & 1.17 & 1.19 \\
\hline \multicolumn{5}{|c|}{ Theil's U } \\
\hline swap vs. RW & 0.71 & - & 0.68 & - \\
\hline SPF vs. RW & - & 0.74 & - & 0.69 \\
\hline swap vs. AR & 0.76 & - & 0.80 & - \\
\hline SPF vs. AR & - & 0.88 & - & 0.92 \\
\hline swap vs. $2 \%$ & 0.78 & - & 0.99 & - \\
\hline SPF vs. $2 \%$ & - & 1.00 & - & 1.02 \\
\hline \multicolumn{5}{|c|}{ Diebold-Mariano forecast accuracy } \\
\hline swap vs. RW & 1.28 & - & 2.49 & - \\
\hline SPF vs. RW & - & 1.34 & - & 1.95 \\
\hline swap vs. AR & 1.37 & - & 1.58 & - \\
\hline SPF vs. AR & - & 1.23 & - & 0.70 \\
\hline swap vs. $2 \%$ & 1.31 & - & 0.08 & - \\
\hline SPF vs. $2 \%$ & - & 0.01 & - & -0.33 \\
\hline
\end{tabular}

Note: The table reports RMSE for the forecasts of HICP (in percentages), as based on inflation Swaps, SPF as well as random walk, autoregressive process and $2 \%$ forecast. Theil's $U$ is computed as the ratio of swap-RMSE and random walk (AR, 2\%) RMSE (ratio below 1 suggests better forecast performance of swaps). Diebold-Mariano test statistics above 1.65 means that forecast performance of inflation swaps is better than the corresponding time series process or $2 \%$ forecast at 10\% significance level. Forecast horizons correspond to the horizons of 1-year and 1-year in one year inflation swaps (i.e., 9 and 21 months respectively) and SPF surveys (1 year and 2 years). The analysed 
samples cover the period: March 2005 - April 2015, which corresponds to 113 (101) monthly forecast error observations for swaps for 9 (21)-month ahead horizon and 36 (32) quarterly forecast error observations for SPF for 1 (2)-year ahead horizon.

Table 4. Comparison of forecast performance of inflation swap rates and SPF with benchmarks - United States

\begin{tabular}{|c|c|c|c|c|}
\hline & 10 months ahead & 4 quarters ahead & 22 months ahead & 8 quarters ahead \\
\hline \multicolumn{5}{|c|}{ Mean Error } \\
\hline swap & 0.47 & - & -0.02 & - \\
\hline SPF & - & -0.06 & - & - \\
\hline RW & -0.31 & -0.32 & -0.58 & -0.59 \\
\hline AR & -0.27 & 0.14 & 0.07 & 0.26 \\
\hline $2 \%$ & 0.14 & 0.14 & 0.02 & 0.05 \\
\hline \multicolumn{5}{|c|}{ Root Mean Squared Error } \\
\hline swap & 2.17 & - & 2.13 & - \\
\hline SPF & - & 1.92 & - & - \\
\hline RW & 2.97 & 3.08 & 2.89 & 2.73 \\
\hline AR & 2.87 & 2.52 & 2.05 & 2.05 \\
\hline $2 \%$ & 1.96 & 1.90 & 1.97 & 1.94 \\
\hline \multicolumn{5}{|c|}{ Theil's U } \\
\hline swap vs. RW & 0.73 & - & 0.74 & - \\
\hline SPF vs. RW & - & 0.62 & - & - \\
\hline swap vs. AR & 0.76 & - & 1.04 & - \\
\hline SPF vs. AR & - & 0.76 & - & - \\
\hline swap vs. $2 \%$ & 1.11 & - & 1.08 & - \\
\hline SPF vs. $2 \%$ & - & 1.01 & - & - \\
\hline \multicolumn{5}{|c|}{ Diebold-Mariano forecast accuracy } \\
\hline swap vs. RW & 1.35 & - & 2.03 & - \\
\hline SPF vs. RW & - & 1.56 & - & - \\
\hline swap vs. AR & 1.30 & - & -1.08 & - \\
\hline SPF vs. AR & - & 1.48 & - & - \\
\hline swap vs. $2 \%$ & -1.42 & - & -0.98 & - \\
\hline SPF vs. $2 \%$ & - & -0.23 & - & - \\
\hline
\end{tabular}

Note: The table reports RMSE for the forecasts of CPI (in percentages), as based on inflation swaps, SPF as well as random walk, autoregressive process and $2 \%$ forecast. Theil's $U$ is computed as the ratio of swap-RMSE and random walk $(A R, 2 \%)$ RMSE (ratio below 1 suggests better forecast performance of swaps). Diebold-Mariano test statistics above 1.65 means that forecast performance of inflation swaps is better than the corresponding time series process or $2 \%$ forecast at 10\% significance level. Forecast horizons correspond to the horizons of 1-year and 1-year in one year inflation swaps (i.e., 10 and 22 months respectively) and SPF surveys (1 year and 2 years). The analysed samples cover the period: March 2005 - April 2015, which corresponds to 113 (101) monthly forecast error observations for swaps for 10 (22)-month ahead horizon and 36 (32) quarterly forecast error observations for SPF for 1 (2)-year ahead horizon.

Comparing mean errors of the forecasts, the analysed inflation expectation measures seem to be unbiased predictors of inflation, with mean errors being relatively close to zero, not exceeding 20 basis points. As regards RMSE of the forecasts, information embedded in short-term inflation swaps and the SPF seems to have value added, as compared with the HICP/CPI forecasts based only on a random walk or AR(1), while the average performance is quite similar to predicting always $2 \%$. (Note 16) This result is also reflected in the values of Theil's U being smaller than one for most performance tests. Diebold-Mariano test statistics shows that the forecasting performance of survey-based inflation expectations is somewhat better than that of statistical time series processes (in line with the findings in Ang, Bekaert, and Wei (2007) for the United States), while inflation swap-based expectations are significant for improving the forecast performance, in particular for longer horizons. However, it needs to be stressed that for most cases, although inflation swaps and SPF have lower forecasting errors, the difference in performance is not statistically significant for the considered samples. (Note 17) This is most likely due to the still relatively short samples, where although on average forecast errors are lower, the size of the sample makes it challenging to find statistically 
significant test results. With respect to the comparison with a $2 \%$ constant forecast, both expectations measures are (statistically speaking) indistinguishable with respect to the forecasting performance, as compared to a constant forecast of $2 \%$. However, this result needs to be read as an average over the whole sample and might not be relevant for periods where large shocks are in place (see, e.g., Figure 5 discussed above). Overall, the results suggest that for both, euro area and the United States, market-based and survey-based measures of inflation expectations are generally informative for forecasting inflation, as compared to usual benchmarks like statistical models or a constant forecast.

\section{Discussion}

Market- and survey-based measures of inflation expectations are commonly used by central banks for a regular analysis of the inflation outlook and the surrounding risks, serving as an important component of information underlying policy considerations. In this respect, they may be seen as complementary sources of information on future inflation, in addition to inflation forecasts based on economic or statistical models. This paper analyses the forecasting performance of measures of inflation expectations for inflation developments.

Our work contributes to the literature by providing evidence that market-based and survey-based measures of inflation expectations are informative source of information for future inflation. One of the main issues faced when assessing the predictive power of survey- and market-based measures of inflation expectations is the number of available observations. While market-based measures have high frequency, they are available only since 2006. The survey indicators like the Survey of Professional Forecasters are available since 1999 for the euro area (and longer for the US), but their frequency is only quarterly. Therefore, only most recently have the samples become long enough to test the forecast accuracy of these types of inflation expectations.

We analyse the forecasting power of market- and survey-based measures of inflation expectations at one year and two years ahead horizons, checking with a Diebold-Mariano test for differences with respect to the benchmark models of random walk, AR-process and a constant forecast of $2 \%$. We find that both, market-based and survey-based measures of inflation expectations are informative predictors of future HICP developments. In particular, although in some cases not statistically significant due to the still short samples, both market-based and survey-based measures outperform statistical approaches to forecasting inflation. This suggests that these measures should be used as informative variables for assessing possible future inflation developments in the central bank and academic analysis.

\section{Acknowledgements}

The views expressed in this paper are not necessarily those of the European Central Bank. We would like to thank the participants of the 35th International Symposium on Forecasting, 2015 European Financial Management Association Conference, and 2015 World Finance Conference, as well as to Jorge Mario Uribe, Thomas Werner, Thomas Westermann, Juan Angel García, and the Editorial Board of the ECB Working Paper Series for helpful comments. We also thank Claudia Marchini for assistance with the data.

\section{References}

Ang, A., G. Bekaert, \& M. Wei. (2007). Do macro variables, asset markets or surveys forecast inflation better?, Journal of Monetary Economics, 54, 1163-1212. https://doi.org/10.1016/j.jmoneco.2006.04.006

Bauer, M. D., \& E. McCarthy. (2015). Can we rely on market-based inflation forecasts?. Federal Reserve Bank of San Francisco Economic Letter, 2015-30.

Bowles, C., R. Friz, V. Genre, G. Kenny, A. Meyler, \& T. Rautanen. (2010). An evaluation of the growth and unemployment forecasts in the ECB Survey of Professional Forecasters. Journal of Business Cycle Measurement and Analysis, 2010(2), 1-28. OECD Publishing, CIRET.

Capistran, C., \& A. Timmermann. (2006). Disagreement and biases in inflation expectations. Working Paper 2006-07, Banco de Mexico.

Clark, T., \& M. McCracken. (2013). Advances in Forecast Evaluation. In Elliott and Timmermann (Eds.), Handbook of Economic Forecasting, Elsevier. https://doi.org/10.1016/B978-0-444-62731-5.00020-8

D“Agostino, A., K. McQuinn, \& K. Whelan. (2012). Are some forecasters really better than others?, Journal of Money, Credit and Banking, 44(4), 715-732. https://doi.org/10.1111/j.1538-4616.2012.00507.x

Deacon, M., A. Derry, \& D. Mirfendereski. (2004). Inflation-indexed securities: bonds, swap and other derivatives $\left(2^{\text {nd }}\right.$ ed.). Wiley Finance Series. Chichester, UK: Wiley https://doi.org/10.1002/9781118673317 
Diebold, F. X. (2013). Comparing Predictive Accuracy, Twenty Years Later: A Personal Perspective on the Use and Abuse of Diebold-Mariano Tests. Manuscript, Department of Economics, University of Pennsylvania.

Diebold, F. X., \& R. S. Mariano. (1995). Comparing Predictive Accuracy. Journal of Business and Economic Statistics, 13(3), 253-63.

Ejsing, J., M. Grothe, \& O. Grothe (2015). Liquidity and credit premia in the yields of highly-rated sovereign bonds. Journal of Empirical Finance, 33, 160-173. https://doi.org/10.1016/j.jempfin.2015.04.001

European Central Bank (2011a). Estimating real yields and break-even inflation rates following the recent intensification of the sovereign debt crisis. Monthly Bulletin of the European Central Bank, December 2011.

European Central Bank. (2011b). Inflation expectations in the euro area: a review of recent developments. Monthly Bulletin of the European Central Bank, February 2011.

European Central Bank. (2012). Assessing the anchoring of longer-term inflation expectations. Monthly Bulletin of the European Central Bank, July 2012.

European Central Bank. (2014a). Inflation risk premia in market-based measures of inflation expectations. Monthly Bulletin of the European Central Bank, July 2014.

European Central Bank. (2014b). Recent developments in inflation forecasts and shorter and longer-term inflation expectations in the euro area. Monthly Bulletin of the European Central Bank, July 2014.

Faust, J., \& J. H. Wright. (2013). Forecasting inflation. In Elliott and Timmermann (Eds.), Handbook of Economic Forecasting, Elsevier.

Fleming, M. J., \& J. R. Sporn. (2013). Trading activity and price transparency in the inflation swap market. Federal Reserve Bank of New York Economic Policy Review, 19(1), 45-57. https://doi.org/10.2139/ssrn.2324235

Genre, V., G. Kenny, A. Meyler, \& A. Timmermann. (2013). Combining expert forecasts: Can anything beat the simple average?, International Journal of Forecasting, 29(1), 108-121.

Gil-Alana, L., A. Moreno, \& F. Perez de Gracia. (2012). Exploring survey-based inflation forecasts. Journal of Forecasting, 31(6), 524-539. https://doi.org/10.1002/for.1235

Hansen, B. E. (2010). Multi-step forecast selection. Working Paper.

Harvey, D., S. Leybourne, \& P. Newbold. (1997). Testing the equality of prediction mean squared errors. International Journal of Forecasting, 13, 281-291. https://doi.org/10.1016/S0169-2070(96)00719-4

Marcellino, M., J. H. Stock, \& M. W. Watson. (2006). A comparison of direct and iterated multistep AR methods for forecasting macroeconomic time series. Journal of Econometrics, 135, 499-526.

McCracken, M. W., \& K. D. West. (2002). Inference about Predictive Ability. In Clements \& Hendry (Eds.), Companion to Economic Forecasting. Oxford: Blackwell.

Meyler, A., \& I. Rubene. (2009). Results of a special questionnaire for participants in the ECB Survey of Professional Forecasters. ECB mimeo.

Pflueger, C. E., \& L. M. Viceira. (2011). Inflation-indexed bonds and the expectations hypothesis. Annual Review of Financial Economics, 3, 139-158. https://doi.org/10.1146/annurev-financial-102710-144843

Smets, F., \& R. Wouters. (2003). An estimated stochastic dynamic general equilibrium model of the euro area. Journal of the European Economic Association, 1, 1123-1175. https://doi.org/10.1162/154247603770383415

Smets, F., \& R. Wouters. (2007). Shocks and frictions in US business cycles: a Bayesian DSGE approach. American Economic Review, 97, 586-607. https://doi.org/10.1257/aer.97.3.586

Stock, J. H., \& M. W. Watson. (2003). Forecasting Output and Inflation: The Role of Asset Prices. Journal of Economic Literature, 41(3), 788-829. https://doi.org/10.1257/jel.41.3.788

Stock, J. H., \& M. W. Watson. (2010). Modeling inflation after the crisis. Proceedings - Economic Policy Symposium - Jackson Hole, Federal Reserve Bank of Kansas City, 173-220. https://doi.org/10.3386/w16488

Trehan, B. (2015). Survey measures of expected inflation and the inflation process. Journal of Money, Credit and Banking, 47(1), 207-222. https://doi.org/10.1111/jmcb.12174 


\section{Appendix}

Table A1. Correlation structure and Granger causality tests between inflation swap rates/SPF and inflation, full sample

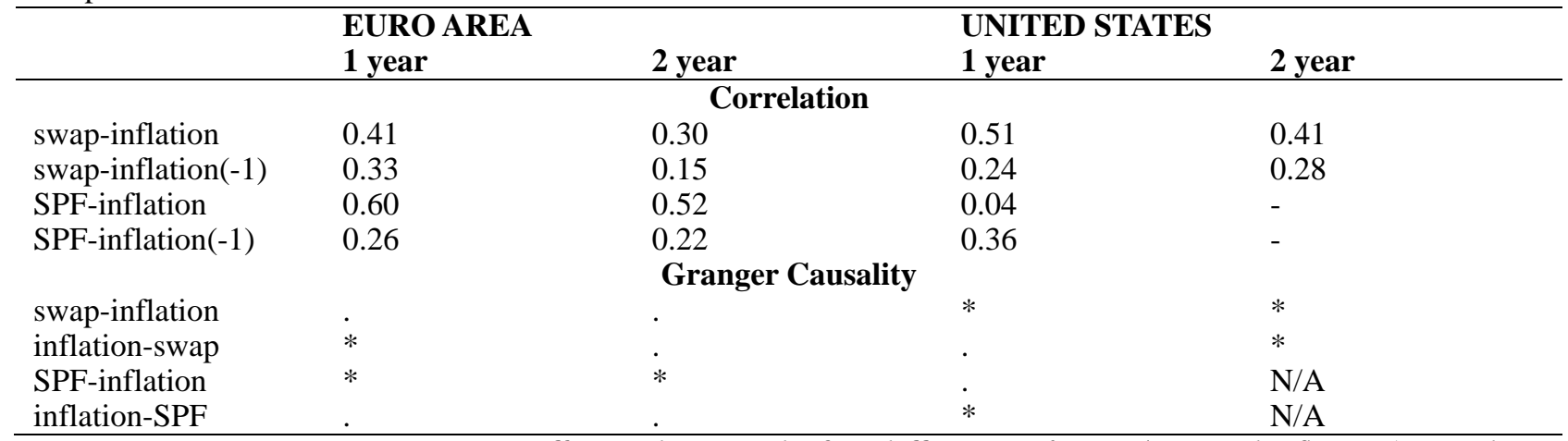

Note: The table reports correlation coefficients between the first differences of swaps/SPF and inflation (in $t$ and in $t$ - 1). F-statistics for the Granger causality test denotes the test for causality from, e.g., swap to inflation, when the row is labelled "swap-inflation". Tests are run on quarterly data for SPF and monthly for inflation swaps. Star reports a statistically significant result at the 99\% confidence level. The analysed samples cover the period: March 2005 - April 2015 for swaps (122 monthly observations), and January 1999 - April 2015 for SPF (65 quarterly observations).

Table A2. Comparison of forecast performance of inflation swap rates and SPF with benchmarks - Euro area, full sample

\begin{tabular}{|c|c|c|c|c|}
\hline & 9 months ahead & 4 quarters ahead & 21 months ahead & 8 quarters ahead \\
\hline \multicolumn{5}{|c|}{ Mean Error } \\
\hline swap & 0.07 & - & -0.19 & - \\
\hline SPF & - & 0.21 & - & 0.12 \\
\hline RW & -0.17 & -0.06 & -0.37 & -0.13 \\
\hline AR & -0.01 & 0.05 & 0.02 & 0.08 \\
\hline $2 \%$ & -0.24 & -0.07 & -0.29 & -0.07 \\
\hline \multicolumn{5}{|c|}{ Root Mean Squared Error } \\
\hline swap & 0.87 & - & 1.16 & - \\
\hline SPF & - & 0.94 & - & 0.97 \\
\hline RW & 1.23 & 1.22 & 1.71 & 1.39 \\
\hline AR & 1.14 & 1.01 & 1.44 & 1.03 \\
\hline $2 \%$ & 1.11 & 0.89 & 1.17 & 0.92 \\
\hline \multicolumn{5}{|c|}{ Theil's U } \\
\hline swap vs. RW & 0.71 & - & 0.68 & - \\
\hline SPF vs. RW & - & 0.77 & - & 0.70 \\
\hline swap vs. AR & 0.76 & - & 0.80 & - \\
\hline SPF vs. AR & - & 0.93 & - & 0.95 \\
\hline swap vs. $2 \%$ & 0.78 & - & 0.99 & - \\
\hline SPF vs. $2 \%$ & - & 1.06 & - & 1.06 \\
\hline \multicolumn{5}{|c|}{ Diebold-Mariano forecast accuracy } \\
\hline swap vs. RW & 1.28 & - & 2.49 & - \\
\hline SPF vs. RW & - & 1.22 & - & 1.87 \\
\hline swap vs. AR & 1.37 & - & 1.58 & - \\
\hline SPF vs. AR & - & 0.73 & - & 1.26 \\
\hline swap vs. $2 \%$ & 1.31 & - & 0.08 & - \\
\hline SPF vs. $2 \%$ & - & -0.56 & - & -1.02 \\
\hline
\end{tabular}

Note: The table reports RMSE for the forecasts of HICP (in percentages), as based on inflation swaps, SPF as well as random walk, autoregressive process and $2 \%$ forecast. Theil's $U$ is computed as the ratio of swap-RMSE and random walk (AR, 2\%) RMSE (ratio below 1 suggests better forecast performance of swaps). Diebold-Mariano test statistics above 1.65 means that forecast performance of inflation swaps is better than the corresponding time series process or $2 \%$ forecast at 10\% significance level. Forecast horizons correspond to the horizons of 1-year and 1-year in one year inflation swaps (i.e., 9 and 21 months respectively) and SPF surveys (1 year and 2 years). The analysed samples cover the period: March 2005 - April 2015, which corresponds to 113 (101) monthly forecast error observations for swaps for 9 (21)-month ahead horizon and January 1999 - April 2015, which corresponds to 61 (57) quarterly forecast error observations for SPF for 1 (2)-year ahead horizon. 
Table A3. Comparison of forecast performance of inflation swap rates and SPF with benchmarks - United States, full sample

\begin{tabular}{|c|c|c|c|c|}
\hline & 10 months ahead & 4 quarters ahead & 22 months ahead & 8 quarters ahead \\
\hline \multicolumn{5}{|c|}{ Mean Error } \\
\hline swap & 0.47 & - & -0.02 & - \\
\hline SPF & - & 0.06 & - & - \\
\hline RW & -0.31 & -0.07 & -0.58 & -0.24 \\
\hline AR & -0.27 & 0.21 & 0.07 & 0.27 \\
\hline $2 \%$ & 0.14 & 0.32 & 0.02 & 0.26 \\
\hline \multicolumn{5}{|c|}{ Root Mean Squared Error } \\
\hline swap & 2.17 & - & 2.13 & - \\
\hline SPF & - & 1.66 & - & - \\
\hline RW & 2.97 & 2.57 & 2.89 & 2.36 \\
\hline AR & 2.87 & 2.07 & 2.05 & 1.78 \\
\hline $2 \%$ & 1.96 & 1.66 & 1.97 & 1.68 \\
\hline \multicolumn{5}{|c|}{ Theil's U } \\
\hline swap vs. RW & 0.73 & - & 0.74 & - \\
\hline SPF vs. RW & - & 0.65 & - & - \\
\hline swap vs. AR & 0.76 & - & 1.04 & - \\
\hline SPF vs. AR & - & 0.80 & - & - \\
\hline swap vs. $2 \%$ & 1.11 & - & 1.08 & - \\
\hline SPF vs. $2 \%$ & - & 1.00 & - & - \\
\hline \multicolumn{5}{|c|}{ Diebold-Mariano forecast accuracy } \\
\hline swap vs. RW & 1.35 & - & $2.03^{\circ}$ & - \\
\hline SPF vs. RW & - & 1.68 & - & - \\
\hline swap vs. AR & 1.30 & - & -1.08 & - \\
\hline SPF vs. AR & - & 1.56 & - & - \\
\hline swap vs. $2 \%$ & -1.42 & - & -0.98 & - \\
\hline SPF vs. $2 \%$ & & 0.00 & & - \\
\hline
\end{tabular}

Note: The table reports RMSE for the forecasts of CPI (in percentages), as based on inflation swaps, SPF as well as random walk, autoregressive process and $2 \%$ forecast. Theil's $U$ is computed as the ratio of swap-RMSE and random walk (AR, 2\%) RMSE (ratio below 1 suggests better forecast performance of swaps). Diebold-Mariano test statistics above 1.65 means that forecast performance of inflation swaps is better than the corresponding time series process or 2\% forecast at 10\% significance level. Forecast horizons correspond to the horizons of 1-year and 1-year in one year inflation swaps (i.e., 10 and 22 months respectively) and SPF surveys (1 year and 2 years). The analysed samples cover the period: March 2005 - April 2015, which corresponds to 113 (101) monthly forecast error observations for swaps for 10 (22)-month ahead horizon and January 1999 - April 2015, which corresponds to 61 (57) quarterly forecast error observations for SPF for 1 (2)-year ahead horizon.

Table A4. Comparison of forecast performance using Hansen (2010) method for estimating MSFE - Euro area

\begin{tabular}{|c|c|c|c|c|}
\hline & 9 months ahead & 4 quarters ahead & 21 months ahead & 8 quarters ahead \\
\hline \multicolumn{5}{|c|}{ Mean Error } \\
\hline swap & 0.23 & - & 0.08 & - \\
\hline SPF & - & 0.30 & - & -0.06 \\
\hline RW & -0.07 & 0.04 & 0.08 & 0.15 \\
\hline AR & 0.13 & 0.34 & 0.44 & 0.56 \\
\hline $2 \%$ & 0.05 & 0.08 & 0.08 & 0.09 \\
\hline \multicolumn{5}{|c|}{ Root Mean Squared Error } \\
\hline swap & 0.89 & - & 1.17 & - \\
\hline SPF & - & 1.16 & - & 1.20 \\
\hline RW & 1.31 & 1.65 & 1.70 & 1.72 \\
\hline $\mathrm{AR}$ & 1.21 & 1.39 & 1.49 & 1.38 \\
\hline $2 \%$ & 0.95 & 1.03 & 1.03 & 1.10 \\
\hline \multicolumn{5}{|c|}{ Theil's U } \\
\hline swap vs. RW & 0.69 & - & 0.69 & - \\
\hline SPF vs. RW & - & 0.70 & - & 0.70 \\
\hline swap vs. AR & 0.74 & - & 0.79 & - \\
\hline
\end{tabular}




$\begin{array}{lllll}\text { SPF vs. AR } & - & 0.83 & - & 0.87 \\ \text { swap vs. } 2 \% & 0.94 & - & 1.13 & - \\ \text { SPF vs. } 2 \% & - & 1.13 & - & 1.09 \\ & & \text { Diebold-Mariano forecast accuracy } & - \\ \text { Swap vs. RW } & 1.27 & - & 1.50 & 1.27 \\ \text { SPF vs. RW } & - & 1.32 & - & - \\ \text { Swap vs. AR } & 1.39 & 1.71 & - & 0.90 \\ \text { SPF vs. AR } & - & - & -1.10 & -1.26 \\ \text { Swap vs. } 2 \% & 0.60 & -2.09 & - & -1.35 \\ \text { SPF vs. } 2 \% & - & & \end{array}$

Note: Forecast errors following Hansen (2010). The table reports RMSE for the forecasts of HICP (in percentages), as based on inflation swaps, SPF as well as random walk, autoregressive process and $2 \%$ forecast. Theil's $U$ is computed as the ratio of swap-RMSE and random walk (AR, 2\%) RMSE (ratio below 1 suggests better forecast performance of swaps). Diebold-Mariano test statistics above 1.65 means that forecast performance of inflation swaps is better than the corresponding time series process or $2 \%$ forecast at $10 \%$ significance level. Forecast horizons correspond to the horizons of 1-year and 1-year in one year inflation swaps (i.e., 9 and 21 months respectively) and SPF surveys (1 year and 2 years). The analysed samples cover the period: March 2005 - April 2015, which corresponds to 94 (76) monthly forecast error observations for swaps for 9 (21)-month ahead horizon and 27 (23) quarterly forecast error observations for SPF for 1 (2)-year ahead horizon.

Table A5. Comparison of forecast performance using Hansen (2010) method for estimating MSFE - United States

\begin{tabular}{|c|c|c|c|c|}
\hline & 10 months ahead & 4 quarters ahead & 22 months ahead & 8 quarters ahead \\
\hline \multicolumn{5}{|c|}{ Mean Error } \\
\hline swap & 0.78 & - & 0.34 & - \\
\hline SPF & - & 0.28 & - & - \\
\hline RW & -0.24 & -0.25 & -0.22 & -0.11 \\
\hline AR & -0.18 & 0.32 & 0.45 & 0.69 \\
\hline $2 \%$ & 0.46 & 0.50 & 0.40 & 0.44 \\
\hline \multicolumn{5}{|c|}{ Root Mean Squared Error } \\
\hline swap & 2.29 & - & 2.30 & - \\
\hline SPF & - & 2.08 & - & - \\
\hline RW & 3.23 & 3.52 & 3.12 & 2.88 \\
\hline $\mathrm{AR}$ & 3.13 & 2.87 & 2.23 & 2.30 \\
\hline $2 \%$ & 2.05 & 2.07 & 2.12 & 2.15 \\
\hline \multicolumn{5}{|c|}{ Theil's U } \\
\hline swap vs. RW & 0.71 & - & 0.74 & - \\
\hline SPF vs. RW & - & 0.59 & - & - \\
\hline swap vs. AR & 0.73 & - & 1.03 & - \\
\hline SPF vs. AR & - & 0.73 & - & - \\
\hline swap vs. $2 \%$ & 1.12 & - & 1.09 & - \\
\hline SPF vs. $2 \%$ & - & 1.01 & - & - \\
\hline \multicolumn{5}{|c|}{ Diebold-Mariano forecast accuracy } \\
\hline swap vs. RW & 1.45 & - & 1.89 & - \\
\hline SPF vs. RW & - & 1.79 & - & - \\
\hline swap vs. AR & 1.40 & - & -0.94 & - \\
\hline SPF vs. AR & - & 1.93 & - & - \\
\hline swap vs. $2 \%$ & -1.46 & - & -0.91 & - \\
\hline SPF vs. $2 \%$ & - & -0.09 & - & - \\
\hline
\end{tabular}

Note: Forecast errors following Hansen (2010). The table reports RMSE for the forecasts of CPI (in percentages), as based on inflation swaps, SPF as well as random walk, autoregressive process and $2 \%$ forecast. Theil's $U$ is computed as the ratio of swap-RMSE and random walk (AR, 2\%) RMSE (ratio below 1 suggests better forecast performance of swaps). Diebold-Mariano test statistics above 1.65 means that forecast performance of inflation swaps is better than the corresponding time series process or $2 \%$ forecast at $10 \%$ significance level. Forecast horizons correspond to the horizons of 1-year and 1-year in one year inflation swaps (i.e., 10 and 22 months respectively) and SPF surveys (1 year and 2 years). The analysed samples cover the period: March 2005 - April 2015, which corresponds to 94 (76) monthly forecast error observations for swaps for 10 (22)-month ahead horizon and 27 (23) quarterly forecast error observations for SPF for 1 (2)-year ahead horizon. 


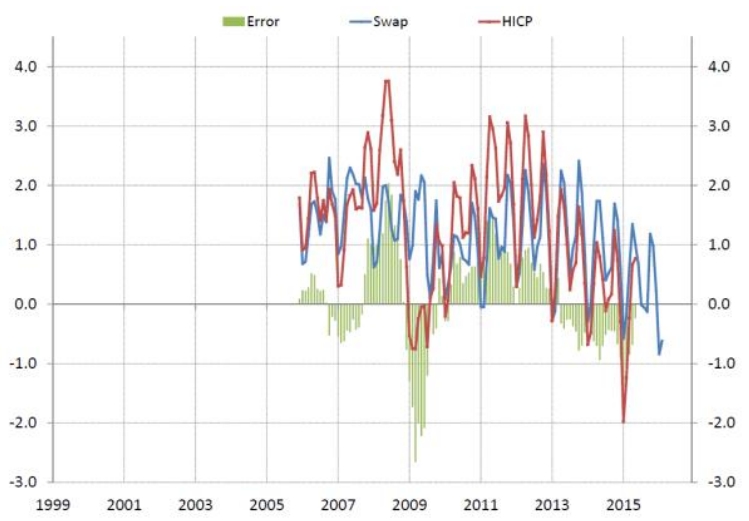

(a) 9-month ahead swap and HICP

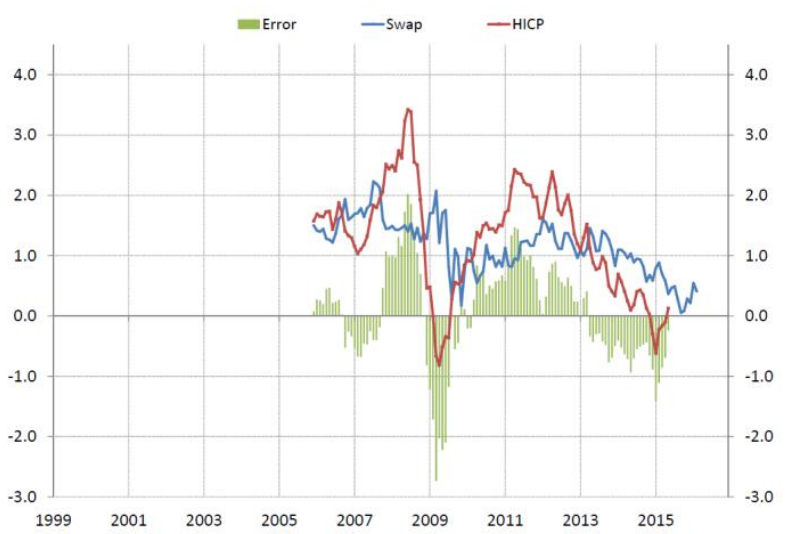

(b) Seasonally adjusted 9-month ahead swap and HICP

Figure A1. One-year ahead inflation forecasts from adjusted swaps

Note: The figure presents a comparison of forecasts, as based on adjusted swaps. Due to the indexation lag of the swap contract, three months out of the forecasted 12-month inflation are already known at the time of pricing the swap. Thus, the forecast component of the swap refers in fact only to the following nine months. Panel (a) shows the forecast and actual inflation for the 9-month ahead period only. Panel (b) corrects for seasonal effects. 


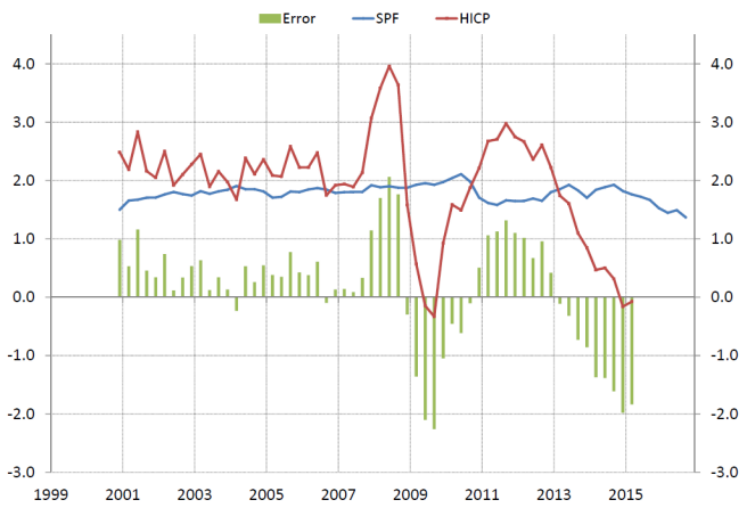

(a) SPF and HICP

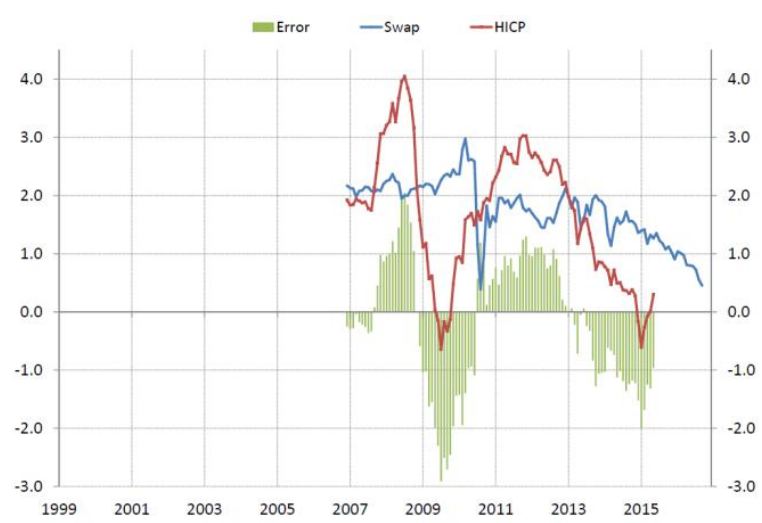

(b) Swap and HICP

Figure A2. Two-year ahead inflation forecasts from surveys and swaps

Note: The figure presents a comparison of forecasts, as based on SPF and swaps with the realised HICP for the euro area. Panel (a) shows the two-years ahead inflation forecast from the SPF. Panel (b) shows the same for the 1-year forward inflation swap rate one year ahead.

\section{Notes}

Note 1. A thorough description of the inflation-indexed securities can be found in Deacon, Derry, and Mirfendereski (2004), while European Central Bank (2011a) provides the methodology to derive inflation expectations based on market prices of inflation-linked and nominal bonds. Although the information derived from inflation bond and swap markets is similar, the pricing of inflation swaps has been in the recent years somewhat less volatile than the pricing of inflation-linked and nominal bonds. This is due to specific market effects, in particular related to the liquidity effects and the supply/demand effects in the bond markets (see, e.g. Ejsing, Grothe, and Grothe (2015)). For this reason, in the regular analysis of market-based inflation expectations for shorter horizons, information based on inflation swaps is usually used.

Note 2. The indexation to the HICP excluding tobacco (HICPxT) rather than the overall HICP (HICP) originated for legal reasons in the French market and was carried over to the euro area market. Although swap data indexed to the overall HICP are available for the euro area HICP, this market is far less actively traded than the standard inflation swaps linked to HICPxT. The choice to focus on the actively traded swap market does not influence the conclusions of the paper, as the analysis using the overall HICP swap data gives similar results (mean forecast error of HICP-swaps is lower, but there is no significant impact on the RMSE).

Note 3. Inflation swaps are also directly traded as zero-coupons, which makes it possible to avoid a model-based estimation, which is needed for bond-based break-even inflation rates (see, e.g. European Central Bank (2011a)). 
Note 4. The US SPF began in 1968 and was initially conducted by the American Statistical Association and the National Bureau of Economic Research. The Federal Reserve Bank of Philadelphia took over the survey in 1990.

Note 5. There is an element of seasonality in the response rate which is lower on average in the Q3 round, conducted in July. This most likely owes to the vacation habits of participants. Bowles et al. (2010) find that there is no noticeable difference in the performance of the SPF in the Q3 round compared with other rounds.

Note 6. Although Bowles et al. (2010) find no noteworthy difference in the mean forecasts from financial and non-financial participants in the ECB SPF, Capistran and Timmermann (2006) present evidence suggesting that among forecasters with an academic affiliation, from industry and from finance in the US Livingston Survey, those from academia have the least dispersed mean forecast errors whilst those from finance are most dispersed.

Note 7. The ECB's SPF respondents also have GDP data for the quarter before this (i.e. they have data for GDP in the third quarter of the previous year in the January round, for the fourth quarter in the April round, etc.) and unemployment data for the month ending each quarter (i.e. they have data for the unemployment rate for November of the previous year in the January round, for February in the April round, etc.). The US SPF has a similar setup.

Note 8 . Of those respondents who update their forecasts regularly according to a calendar, over 50\% reported that their forecasts are updated on a quarterly basis, with a slightly smaller share (35\%) updating them on a monthly basis. When asked, most respondents indicated that they provide their latest available forecast in each SPF round, with only a small proportion preparing a new forecast for the SPF. However, a number of respondents (27\%) said that they may partially update their forecasts when responding to the SPF.

Note 9. Using the ECB SPF, Genre et al. (2013) test a wide variety of forecast combination techniques based on principal components and trimmed means, performance-based weighting, and least squares estimates of optimal weights, as well as Bayesian shrinkage. Whilst at first glance they found some evidence of an improvement for inflation forecast; nonetheless, when they accounted for the effect of multiple model comparisons through Whites reality check these improvements were not robust. Similarly, using the US SPF, D“Agostino et al. (2012) tried to see whether they could identify ex ante whether some forecasters perform better than others. Interestingly they found limited evidence for forecasts better than average although there was some evidence that a relatively small group of forecasters perform very poorly in a statistically significant sense.

Note 10. This information is also provided as a reference in the questionnaire.

Note 11. At any point in time $\mathrm{t}$, the year-on-year rate of inflation is equal to the product of the month-on-month inflation in that month and the previous eleven months. For small changes, the product can be approximated by the

sum, i.e., yoy $_{t} \equiv\left[\Pi_{i=0}^{11}\left(1+\operatorname{mom}_{t-i}\right)\right]-1 \cong \sum_{i=0}^{11} \operatorname{mom}_{t-i}$. Owing to different publication lags in the United States there are

some differences with respect to the euro area, most notably swap participants know just two months of the twelve months that that add up to the year-on-year inflation rate.

Note 12. Part of the autocorrelation owes to the overlapping forecast horizons. Thus a shock in one period can impact on the forecast error from a number of rounds.

Note 13. For the United States, the indexation lag is also 3 months, but due to the lack of CPI flash estimate, this implies that only two monthly CPI releases are known by the end of the month, when the swap rate is recorded.

Note 14. For generating forecasts, we use an iterated forecast (see, e.g. Marcellino, Stock, and Watson (2006) for a discussion of performance).

Note 15. Regarding the test statistics, Faust and Wright (2013) use a slightly modified Diebold and Mariano (1995) test statistics, following Clark and McCracken (2013). For an overview of other methods on forecast comparisons, see also McCracken and West (2002). In this analysis, Diebold and Mariano (1995) test statistics is used, not least in view of the work by Diebold (2013), who argues that the test is informative to compare out-of-sample forecasts, in particular model-free forecasts, which is the case for HICP forecast based on inflation swap rates.

Note 16. These results confirm that, although inflation swaps are indexed to HICPxT rather than overall HICP, this does not impair their forecast performance for actual HICP, as explained in Section 2.

Note 17. Still, one has to keep in mind that one of the benchmark models, i.e., the AR model, has a significant advantage of being estimated for the whole sample, which allows to avoid the issue of parameter instability. 